\title{
Cooperation of Science and Business in Order to Organize High-Tech Production in the Regions of the Russian Federation
}

\author{
Marina V. Shinkevich \\ Department of Logistics and Management \\ Kazan National Research Technological University \\ Kazan, Russia \\ leotau@mail.ru \\ Igor A. Raiskii \\ Postgraduate \\ Kazan National Research Technological University \\ Kazan, Russia \\ raiskiyia@mail.ru
}

\author{
Farida F. Galimulina \\ Department of Logistics and Management \\ Kazan National Research Technological University \\ Kazan, Russia \\ 080502e_m@mail.ru
}

\author{
Tatyana V. Malysheva \\ Department of Logistics and Management \\ Kazan National Research Technological University \\ Kazan, Russia \\ tv_malysheva@mail.ru \\ Alsu A. Lubnina \\ Department of Logistics and Management \\ Kazan National Research Technological University \\ Kazan, Russia \\ alsu1982@yandex.ru \\ Madina A. Agisheva \\ Department of physics \\ Kazan National Research Technological University \\ Kazan, Russia \\ zamilid@kstu.ru
}

\begin{abstract}
The article discusses the regional aspects of the formation of cooperative ties between science and business. The level of cooperation of enterprises with scientific and educational organizations is presented as an important criterion for the organization of high-tech production. The relevance of the article lies in the need to solve the problems of managing joint innovative projects in Russian regions. The purpose of the article is to identify trends and factors that influence the development of cooperative ties in regional production systems of various levels of manufacturability. As the main research methods, the article used the description method to determine the level and trends of innovative development of Russian regions; the method of correlation analysis, which established the factors that have the greatest influence on the degree of cooperation of scientific organizations and industrial enterprises in the development of technological innovations. The article presents an analysis of the dynamics of innovative development of the industrial sector of the Russian regions; the interrelation of factors affecting the degree of cooperation between science and business in the development of technological innovations is determined. The materials of the article can be used in the development of organizational and managerial decisions aimed at enhancing the innovative development of territories, the organization of high-
\end{abstract}

tech industries, taking into account the cooperation of scientific organizations and business.

Keywords: high-tech production, regional development, organization of production, technological innovation, cooperative ties, joint projects

\section{INTRODUCTION}

The creation of a productive alliance of science and business is by far the most promising direction for the development of the Russian industry. An economy can be called innovative when industrial production is based on modern scientific research, and various innovations are used in business without losing relevance. The positive impact of industrial and scientific cooperation on the processes of innovative activity in the regions and industries is noted by most researchers. It is these networks that connect representatives of science and business that form the basis for the development of high-tech industries. The most important advantage in the formation of innovative systems is the stability of the links between science and business. In this regard, innovative networks are in the focus of attention of Russian and European theorists and practitioners. On the basis 
of universities and enterprises, business incubators, science parks and regions of science are being created, which are one of the main forms of interaction between science and business.

The changed conditions for the development of high-tech industries have led to the evolution of the main factors of production in the high-tech market, as well as to the adaptation of strategies for the development and production of innovative products. The development of the economy is undergoing qualitative changes that are associated with the transition from the level of industrial development to a new post-industrial level. A new level is characterized by an increase in the degree of intellectualization and informatization of all technological processes. The category "high technology" uses concepts such as high technology, innovative technology. These technologies are based on deep and advanced scientific knowledge that arises from the effective interaction of science and business. This concept includes highly efficient engineering activities.

In a number of regions of the Central, North-Western, Volga, Ural, Siberian and Far Eastern federal districts, 25 innovative territorial clusters are located. These clusters carry out activities in the following areas of technological specialization: "Nuclear and radiation technologies", "Aircraft and spacecraft production, shipbuilding", "Pharmaceuticals, biotechnologies and the medical industry", "New materials", "Chemistry and petro chemistry", "Information technologies and electronics. Within the framework of innovation clusters, a close interaction of many economic agents (business, research organizations, universities) is carried out. At the same time, in terms of cooperation or participation in joint innovative projects among the countries of the European Union, Russia is only on the 14 th place $(36 \%$ of organizations), while in the Great Britain, Belgium, Cyprus, Slovenia this indicator is 50-70\% (Federal State Statistics Service, from: http://www.gks.ru).

\section{LITERATURE REVIEW AND RESEARCH METHODS}

The problems of the development of high-tech industries are considered in the works of scientists in various fields, including the organization of international network structures in the high-tech industry [1], the study of problems of technological integration in the manufacturing industry [2], the management of development programs [3], and the improvement of energy efficiency in meso- and micro levels [4], the study of the impact of scientific developments on productivity [5], the organization of production of competitive products [6], the sustainable development of competitive enterprises through innovative development strategy [7].

There are developments by scientists in the field of innovative development at the regional level, namely the study of industry-specific innovative potential [8], a structured analysis of regional innovations [9], modeling of innovation management in a regional industrial complex [10], the study of regional sustainability [11], the identification of problems of a differentiated approach to the management of innovative development in the Russian regions [12].

The experience of cooperation between science and business is presented in the context of the following areas of knowledge: modeling the processes of knowledge generation in the digital economy [13], innovative and technological cooperation in the framework of flexible production [14], the development of incubators for the resource base of technological enterprises [15], the study of innovative ecosystems in science, technology and business [16], the formation of a network model of the value chain [17], the commercialization of high technology innovations [18].

An analysis of the work of scientists in the cooperation of science and business with the aim of organizing high-tech industries has shown that the mechanisms and tools used to manage innovative development do not currently fully take into account the possibilities of using the potential of network integration of scientific organizations and the business community in the regions. In some cases, this does not make it possible to give scientifically sound recommendations for enhancing innovation and reduces the level of manufacturability and production efficiency. In this regard, the task of developing an organizational mechanism and priority areas for the interaction of science and business in the framework of innovative projects is essential for developing the theoretical foundations for the development of high-tech industries.

As a research tool, the work used a functional analysis, systematization and generalization of facts and concepts, a method of graphic images, a method of expert assessments. To identify and systematize the factors affecting the degree of cooperation between science and business in the development of technological innovations in the Russian regions, we used the method of correlation analysis, which allows us to determine the factors that have the greatest influence on the degree of cooperation of scientific organizations and industrial enterprises in the development of technological innovations.

Correlation analysis allows you to determine the presence (absence) of the statistical relationship of variables, where each specific value of the variable $\mathrm{X}$ corresponds to a certain value of $Y$. The correlation of the two quantities may indicate the existence of a common cause, although the phenomena themselves do not directly interact. A quantitative assessment of the direction and tightness of linear communication is carried out by calculating the linear correlation coefficient. In this study, the square method (Pearson) was used. The formula for calculating the correlation coefficient is as follows:

$$
\operatorname{Rxy}=\frac{\sum \mathrm{dx} \bullet \mathrm{dy}}{\sqrt{\sum d x^{2} \cdot \sum d y^{2}}},
$$

where $R x y$ - correlation coefficient between the statistical series $X$ and $Y ; d x$ - the deviation of each of the numbers of the statistical series $X$ from the arithmetic mean; $d y$ - the deviation of each of the numbers of the statistical series $Y$ from the arithmetic mean.

Depending on the strength of the bond and its direction, the correlation coefficient can range from 0 to $1(-1)$. The closer the level of the correlation coefficient to 1 or $(-1)$, the closer the measured direct or feedback. A qualitative 
expressed. For the total level of innovation activity, the maximum values are observed in the Volga (12.3\%), Central (11.9\%), Ural (10.9\%) federal districts. The middle group includes the North-Western, Far Eastern and Siberian districts with the level of innovative activity, respectively, 9.0\%, 9.0\% and $8.2 \%$. A similar indicator in the North Caucasus Federal District is $3.2 \%$.

The proportion of organizations participating in joint innovation projects in federal districts varies from $1.5 \%$ in the North Caucasus District to $4.3 \%$ in the Urals District (table II).

TABLE II. TRENDS IN THE INNOVATIVE DEVELOPMENT OF ENTERPRISES OF THE FEDERAL DISTRICTS OF THE RUSSIAN FEDERATION

\section{RESULTS AND DISCUSSION}

The analysis of data on the cooperation of industrial enterprises with scientific and educational organizations in the development of technological innovations shows a close relationship between the participation of industries in joint innovative projects and their level of manufacturability. As can be seen from table 1, the largest number of enterprises participating in cooperation with science and education is observed among medium-tech low-level industries - 50.5\% and $40.5 \%$, respectively. This is the production of rubber and plastic products, metallurgical production, production of building materials and so on.

High-tech manufactures and medium-tech manufactures of a high level have somewhat lower values, which is probably due to the presence of a number of enterprises with their own scientific and educational base, as well as already acquired developments and technologies that are at the stage of commercialization.

Among low-tech industries, only $14.3 \%$ of enterprises participate in joint projects with scientific organizations and $10.7 \%$ - with educational institutions. This group includes food production, textile production, publishing, furniture manufacturing (table I).

TABLE I. COOPERATION OF INDUSTRIAL ENTERPRISES OF THE RUSSIAN FEDERATION WITH SCIENTIFIC AND EDUCATIONAL ORGANIZATIONS IN THE DEVELOPMENT OF TECHNOLOGICAL INNOVATIONS

\begin{tabular}{|l|l|l|}
\hline \multicolumn{1}{|c|}{$\begin{array}{c}\text { The level of } \\
\text { manufacturability }\end{array}$} & $\begin{array}{c}\text { The share of } \\
\text { enterprises } \\
\text { participating in joint } \\
\text { projects with scientific } \\
\text { organizations, \% }\end{array}$ & $\begin{array}{c}\text { The share of } \\
\text { enterprises } \\
\text { participating in joint } \\
\text { projects with } \\
\text { educational } \\
\text { organizations, \% }\end{array}$ \\
\hline $\begin{array}{l}\text { High-tech } \\
\text { production }\end{array}$ & 45.1 & 29.7 \\
\hline $\begin{array}{l}\text { High-tech mid- } \\
\text { level } \\
\text { manufacturing }\end{array}$ & 38.4 & 21.5 \\
\hline $\begin{array}{l}\text { Low-tech mid- } \\
\text { level } \\
\text { manufacturing }\end{array}$ & 50.5 & 40.2 \\
\hline $\begin{array}{l}\text { Low-tech } \\
\text { production }\end{array}$ & 14.3 & 10.7 \\
\hline $\begin{array}{l}\text { Compiled by the authors according to Federal State Statistics Service, from: } \\
\text { http://www.gks.ru }\end{array}$ & \multicolumn{2}{|l}{} \\
\hline
\end{tabular}

The differentiation of innovative development by regions and districts of the Russian Federation is significantly

\begin{tabular}{|l|l|l|l|}
\hline $\begin{array}{c}\text { Federal } \\
\text { districts of } \\
\text { Russia }\end{array}$ & $\begin{array}{c}\text { The total level of } \\
\text { innovative } \\
\text { activity of } \\
\text { organizations, } \%\end{array}$ & $\begin{array}{c}\text { The proportion } \\
\text { of innovative } \\
\text { organizations } \\
\text { acquiring } \\
\text { equipment, } \%\end{array}$ & $\begin{array}{c}\text { The proportion } \\
\text { of organizations } \\
\text { participating in } \\
\text { joint projects, \% }\end{array}$ \\
\hline Central & 11.9 & 53.7 & 3.5 \\
\hline $\begin{array}{l}\text { North- } \\
\text { Western }\end{array}$ & 9.0 & 43.6 & 3.2 \\
\hline South & 10.0 & 51.0 & 2.0 \\
\hline $\begin{array}{l}\text { North } \\
\text { Caucasian }\end{array}$ & 3.2 & 40.0 & 1.5 \\
\hline Volga & 12.3 & 66.7 & 3.9 \\
\hline Ural & 10.9 & 50.0 & 4.3 \\
\hline Siberian & 8.2 & 33.3 & 3.0 \\
\hline Far Eastern & 9.0 & 53.3 & 2.0 \\
\hline $\begin{array}{l}\text { Compiled by the authors according to Federal State Statistics Service, from: } \\
\text { http://www.gks.ru }\end{array}$ & \\
\hline
\end{tabular}

The creation of an effective interaction between science and business is by far the most promising direction for the development of an innovative economy in Russia. The positive impact of industrial and scientific cooperation on the processes of innovative activity in the regions is noted by most researchers [19]. This area has the institutional and legislative foundations in the framework of the Decree of the Government of the Russian Federation No. 218 of 04/09/2010, aimed at the development of cooperation between science and business. Promoting the transfer of scientific results and new technologies is a prerequisite for socio-economic progress, and the development of cooperative ties is a factor in increasing the efficiency of spending on science in general, including state investments.

The level of development of cooperative ties in the Russian regions varies and has certain specificity. To identify factors affecting the degree of cooperation between science and business in the development of technological innovations, we use the method of correlation analysis. As variables, in our opinion, to a certain extent, have an impact on the level of cooperation of enterprises, we will take the following parameters:

$y$ - the proportion of organizations participating in joint projects to carry out research and development,\% (effective attribute);

$\mathrm{x}_{1}$ - the number of personnel engaged in research and development per research organization, person; 


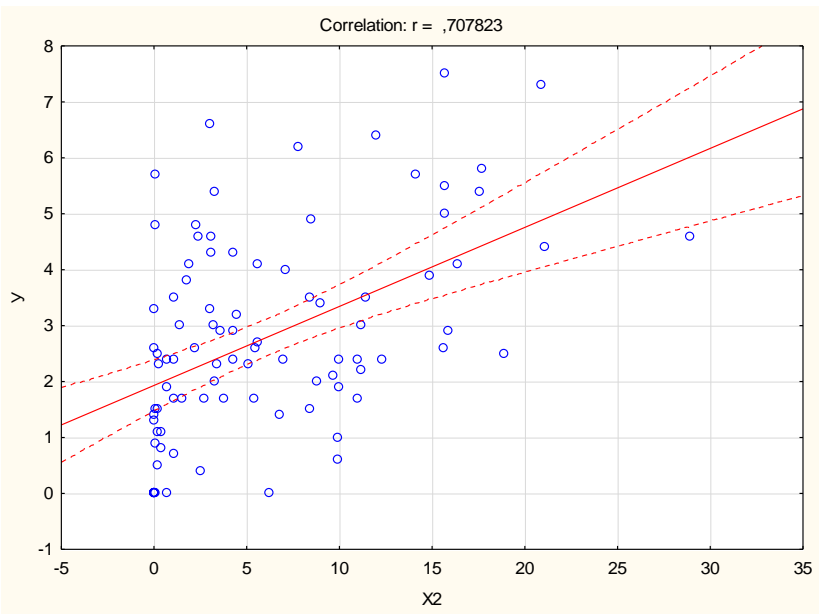

TABLE III. MATRIX OF PAIR CORRELATIONS. CHEDDOCK SCALE

\begin{tabular}{|c|c|c|c|c|c|c|}
\hline & \multicolumn{2}{|c|}{$\begin{array}{l}y-\text { the proportion of } \\
\text { organizations involved } \\
\text { in joint projects to } \\
\text { carry out research and } \\
\text { development, } \% \\
\text { (effective sign) }\end{array}$} & $x_{1}$ & $\mathbf{x}_{2}$ & $\mathbf{x}_{3}$ & $x_{4}$ \\
\hline $\mathrm{y}$ & \multicolumn{2}{|l|}{1} & & & & \\
\hline $\mathrm{x}_{1}$ & 0,6249 & $\begin{array}{l}\text { average direct } \\
\text { relationship }\end{array}$ & 1 & & & \\
\hline $\mathrm{x}_{2}$ & 0,7078 & $\begin{array}{l}\text { high direct } \\
\text { relationship }\end{array}$ & 0,3214 & 1 & & \\
\hline $\mathrm{x}_{3}$ & 0,5137 & $\begin{array}{l}\text { average direct } \\
\text { relationship }\end{array}$ & 0,2092 & $\overline{-}, 0874$ & 1 & \\
\hline $\mathrm{x}_{4}$ & 0,3044 & $\begin{array}{l}\text { weak direct } \\
\text { relationship }\end{array}$ & 0,2425 & 0,6208 & $\overline{0}, 0856$ & 1 \\
\hline
\end{tabular}

The matrix of paired correlations and the assessment of the tightness of the relationship between the productive trait and the factors selected by us are presented in Table 3. As can be seen, the highest impact on the level of development of cooperation between science and business (correlation coefficient 0.71 ) is shown by the specific costs of research and development of research organizations. A less close influence is exerted by the number of personnel engaged in research and development on one research and development organization (correlation coefficient 0.62). Financing technological innovations in industrial companies also plays a significant role in the implementation of joint science and business projects (correlation coefficient 0.51).

The coefficient of inventive activity, defined as the number of patent applications filed by domestic applicants with the patent office per 100 researchers, has only a weak effect on the level of cooperation (correlation coefficient 0.30). At the same time, this factor in the countries of the European Union plays a more significant role in innovative development, in particular in the implementation of joint industrial and scientific projects, commercialization of developments (figures 1,2).

Fig. 1. Scatter chart: dependence of the level of cooperation of organizations $(\mathrm{Y})$ on the costs of research and development of research organizations $\left(\mathrm{X}_{2}\right)$

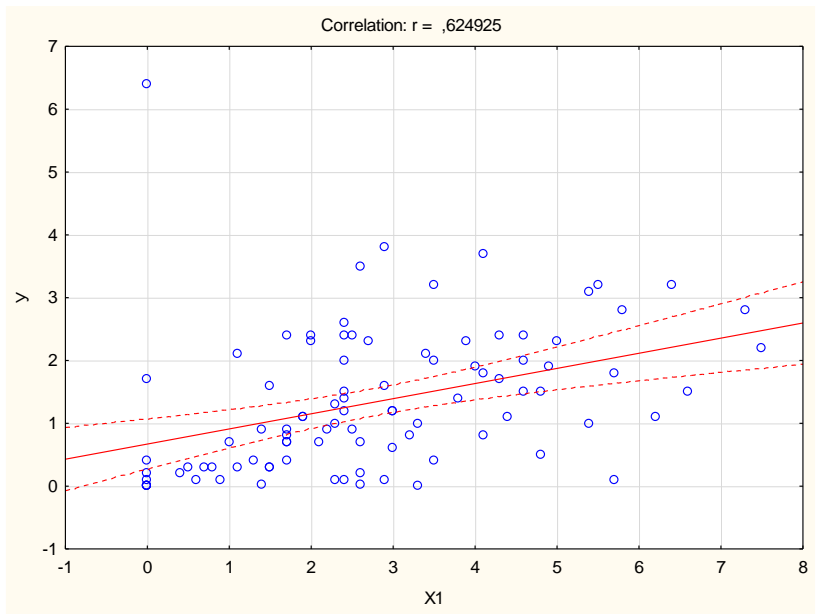

Fig. 2. Scatter chart: dependence of the level of cooperation of organizations (Y) on the availability of personnel engaged in research and development $\left(\mathrm{X}_{1}\right)$

The scattering diagrams show the dependence of the specific gravity of the organizations participating in joint projects on research and development on the most influential factors - the cost of research and development of research organizations and the availability of personnel engaged in research and development. As can be seen, according to the parameters $X_{2}$ and $X_{1}$ relative to the resulting attribute $Y$, a pattern of a combination of non-stationary random processes is observed. Variables develop in one direction and many points corresponding to the observed values of indicators are concentrated, with some exceptions, near the line of best fit with a certain amount of displacement. At the same time, the presence of bias, or in other words, the absence of a close linear relationship across the totality of the studied regions, can partly be explained by random errors associated with the difficulties of adequately measuring certain processes and phenomena.

\section{CONCLUSION}

Thus, the most significant factors in the interaction of business and science are intellectual and financial resources. The accumulated human capital of research organizations is 
- It is necessary to develop a mechanism for providing advisory assistance in developing corporate strategies and cooperation models for innovatively active industrial enterprises. The likelihood of cooperation with scientific organizations and the implementation of scientific results in practical activities are higher for large and technologically advanced companies, effective mechanisms for managing intellectual property.

However, despite the active efforts of the state, stable schemes for the interaction of science and business in Russia have not yet been established. The development of the practice of multilateral network contacts is hindered by a number of internal restrictions and problems of an economic, technological and institutional nature:

- low innovation activity of organizations;

- insufficient demand for scientific results in the economy;

- unbalanced institutional structure of the scientific network with the dominance of independent research institutes;

- functional isolation and inconsistency of research strategies of universities, scientific organizations and business;

- fragmentation and inconsistency of the legislative framework, institutional infrastructure;

- industry and regional imbalances and more.

An analysis of the influence of various factors on the level of cooperation between Russian industrial enterprises and knowledge producers showed that the propensity of a business to partner with research centers and universities is directly dependent on the accumulated intellectual and human capital and the technological level of production. Financially stable organizations that invest resources in scientific development and technological innovation and link development prospects with access to the Russian and world markets more often establish cooperative ties with scientific organizations.

\section{RECOMMENDATIONS}

In order to strengthen cooperative ties between scientific organizations and business, the following areas of impact at the state and corporate levels are recommended:

- At the level of state regulation, a management system in the field of science and technology, including horizontal, target (vertical) and network tools, needs to be reoriented to expand cooperative processes and the emergence of new partnerships. Promoting existing contracts also requires attention, but primary cooperation should be a priority.

- The company's decision to commercialize scientific results and technologies must be linked to government support measures. This also includes network support measures, namely the creation and development of technology platforms, support for territorial innovation clusters, information networks.

- Regulation of innovative business should be based on a comprehensive policy with the inclusion of additional regulators [20]. However, it should be borne in mind that coordination and management of too many instruments can lead to high administrative costs for management bodies, creates risks and uncertainty, and complicates the functioning of universities and research organizations.

- In the context of a limited budget, the implementation of a set of measures to support cooperation between business and science should have clear goals, target indicators, and trajectories for their achievement. At the same time, it is important to strike a balance between instruments for stimulating demand from the business side for scientific results and their proposals from science, with a view to their practical use in production.

The contribution of the authors to the development of the problem of enhancing the interaction between science and business is to identify trends and factors influencing the development of cooperative ties in the regional production systems of the Russian Federation at various levels of manufacturability and financial stability.

The novelty of the author's proposals consists in revealing the direct correlation dependence of partnership between business and research centers on the accumulated intellectual capital and technological level of production, as well as generalizing the directions for strengthening cooperative ties between science and entrepreneurship at the state and corporate level.

The results of the study can be used by the international scientific community and entrepreneurs in solving organizational and managerial tasks to enhance the innovative development of the industrial sector of the territories with an emphasis on enhancing cooperation between science and business in terms of implementing joint innovative projects.

\section{REFERENCES}

[1] M. Smith, G. Matthew, and S. Gorgoni, "International production and trade in a high-tech industry: A multilevel network analysis", Social networks, Oct. 2019, vol. 59, pp. 50-60.

[2] A. Miller and M. Miller, "Study of the problems of technological integration in the manufacturing industry in Russia", Strategic management, 2019, vol. 24, pp. 33-42.

[3] O. B. Braginsky, G. M. Tatevosyan, and S. V. Sedova, "Managing Developmental Programs (on the Example of the Chemical Industry)", Economics and mathematical methods, Jul-Sep. 2019, vol. 55, issue: 3, pp. 74-85. 
[13] M. V. Vlasov, "Modeling knowledge generation processes in a digital economy conditions", Conference: 1st International Scientific Conference on Modern Management Trends and the Digital Economy From Regional Development to Global Economic Growth Location: Inst Int Relat, 2019, vol. 81, pp. 247-252.

[14] A. Martinez Sanchez, M. Perez-Perez, and S. Vicente-Oliva, "Agile production, innovation and technological cooperation Overlapping priorities of manufacturing firms", Baltic Journal of Management, 2019, vol. 14, issue: 4, pp. 597-615.

[15] A. Yusubova, P. Andries and B. Clarysse, "The role of incubators in overcoming technology ventures' resource gaps at different development stages", R \& D Management, 2019, vol. 49, issue: 5, pp. 803-818.

[16] G. Xu, Y. Wu, and T. Minshall, "Exploring innovation ecosystems across science, technology, and business: A case of 3D printing in China", Technological Forecasting and Social Change, 2018, vol. 136, pp. 208-221.

[17] A. I. Shinkevich, T. V. Malysheva, E. N. Ryabinina, N. V. Morozova, G. N. Sokolova, I. A. Vasileva, and I. I. Ishmuradova, "Formation of Network Model of Value Added Chain Based on Integration of Competitive Enterprises in Innovation-Oriented Cross-Sectorial Clusters", International Journal of Environmental and Science Education, 2016, vol.17, pp. 10347-10364.

[18] Y. Yang, H. Chen, and Q. Zhang, "The Commercialization of University and Research Institutes' Science-Based Innovations: The Four Successful Chinese Cases", Journal of Industrial Integration and Management: Innovation \& Entrepreneurship, Sent. 2019, vol.3, issue: 3 .

[19] A. I. Shinkevich, T. V. Malysheva, E. V. Zelenkina, O. A. Dmitrieva, and V. I. Kurdyumov, "Development and concentration efficiency study of enterprises innovation activity in real sector of economy", Eurasian Journal of Analytical Chemistry, 2017, vol.12, N 7B, pp. 1347-1356.

[20] G. Dimitrova, "Competitiveness of the higher education institutions in the context of integration between science, education, and business", Strategies for Policy in Science and Education, 2019, vol. 27, Issue: 4, pp. 369-380.

12] M. V. Rajskaya, A. A. Sagdeeva, Yu. V. Panteleeva, T. V. Malysheva, and I. G. Ershova, "Differentiated approach problems to innovative development management in Russian regions", Humanities and Social Sciences Reviews, 2019, vol. 7, issue: 4, pp. 1262-1268. 